
\title{
25 Research Square \\ The Quiet Crisis of PhDs and COVID-19: Reaching the financial tipping point.
}

Rebecca L. Johnson ( $\square$ rebecca.johnson@sydney.edu.au )

The University of Sydney https://orcid.org/0000-0001-7321-0744

\section{Ross A. Coleman}

The University of Sydney https://orcid.org/0000-0003-4136-5914

Nicole H. Batten

The University of Sydney https://orcid.org/0000-0002-7255-6169

\section{Djuna Hallsworth}

The University of Sydney https://orcid.org/0000-0003-4621-9828

\section{Emma E. Spencer}

The University of Sydney https://orcid.org/0000-0001-9415-0824

\section{Research Article}

Keywords: COVID-19, Doctoral students, higher education policy, student retention, research workforce, $\mathrm{PhD}$ financial precarity.

Posted Date: July 8th, 2020

DOl: https://doi.org/10.21203/rs.3.rs-36330/v2

License: (c) (i) This work is licensed under a Creative Commons Attribution 4.0 International License. Read Full License 


\section{Abstract}

Before the COVID-19 crisis, existing high levels of financial concerns amongst PhD students increased their vulnerability to disruptive events. Impacts from the pandemic have increased their financial stress to the point that may result in many being forced to exit research studies. An exodus of doctoral students now would impact our future research capacity. The effects of the unfolding crisis on research students at a research-intensive Australian university was documented by a group of doctoral candidates who received 1,020 survey responses from their cohort. Here we show that the pandemic has severely affected research candidates and argue that these results have notable implications for a future research workforce. We found that $75 \%$ of students expect to experience financial hardship as a result of the pandemic. Consequently, $45 \%$ report being pushed beyond their financial capacities and expect to be forced to disengage from their research within six months. Comparative pre-COVID data from an Australian national survey, reports research student disengagement of $20 \%$ over four years. The $25 \%$ increase of expected disengagement, in a much-reduced period, signals a deeper PhD crisis. Swift intervention is required to avert substantial impacts to the pipeline of research talent.

\section{Introduction}

An April 2020 survey of 1020 research students on how the COVID-19 crisis impacted them provides a stark warning for institutes that rely on a robust research workforce. Pre-COVID-19 studies into the doctoral candidate experience show that many students were already experiencing financial concerns(Lauchlan 2019; Universities Australia 2018; Sverdlik et al. 2018). In a 2017 Australian national survey, $57 \%(n=5874)$ of research students reported finances to often be a "source of worry" (Universities Australia 2018). New data reported on here indicate $75 \%$ of research students are now expecting to experience "financial hardship" as a result of the pandemic. Types of hardships respondents expect to experience include inability to pay for accommodation, medicines, utilities, meals, and carer responsibilities. A consequence of so many students unable to afford living necessities is that nearly half $(45 \%, n=454)$ expect to be forced to disengage from research within the next six months. Such a severe disruption to the research community may have longer-term consequences for essential advances in research innovation and knowledge development crucial to governments, corporations, and universities.

The primary data reported on here came from a survey conducted by several PhD candidates at a large, research-intensive university in Australia. They sought to document the research students' experience of the COVID-19 pandemic, a disruptor unique in the lived experience of research organisations. Our analysis of that data in context of pre-COVID-19 studies of the research student experience indicate the pandemic has pushed students to a tipping point that may cause a decline in the global research workforce.

\section{Value of PhD candidates to the workforce.}


PhD students play a pivotal role in economic growth, innovation, and knowledge advancement (OECD 2019). Prior to the pandemic, the total fiscal impact from research and development (R\&D) in the eight leading universities in Australia contributed $\$ 24.5$ billion per annum to the economy (Conlon et al. 2018). Productivity spillover of university research in Australia results in every AUD\$1 invested contributing AUD $\$ 10$ to the economy (Conlon et al. 2018). Spillovers include collaborations between universities and organisations, internationally published findings, and contribution of highly-skilled graduates to a global research workforce (Conlon et al. 2018). University research outcomes are reliant on the work contributions of PhD candidates (Horta et al. 2018); in Australia, research students make up $57 \%$ of university teams (Norton et al. 2018). Additionally, the workforce outside of academia is increasingly employing doctoral holders and relies on a continual supply of graduates. For example, by 2015 the United States saw more than half of PhD graduates employed by government and businesses (McCarthy and Wienk 2019). As the world emerges from the pandemic, it will rely heavily on the work of researchers from many fields to develop strategies and innovations for rebuilding economies, health systems and social structures.

\section{The PhD crisis waiting to happen.}

Research students have been existing in a state of financial precarity for many years (Sverdlik et al. 2018; Guthrie et al. 2018; Evans et al. 2018). Precarity is characterised by living with persistent insecurities around employment, income, and living necessities; a state that increases vulnerability to major disruptive events, such as a pandemic. Living in financial precarity is similar to living on the edge of a financial cliff, replete with all the anxieties and health disorders that brings. Most studies into the experience of students in higher education are focused on the very different journey of coursework students(Sverdlik et al. 2018) despite large increases in the number of PhD candidates in the last two decades (OECD 2019; Universities Australia 2019; Norton et al. 2018). Specific research into doctoral studies evidences experiences marred by isolation, high anxiety, severe depression, and other psychiatric disorders (Evans et al. 2018; Levecque et al. 2017; Virtanen et al. 2017; Woolston 2019) as well as increased physical health impacts (Kernan et al. 2011; Juniper et al. 2012). Less research has been conducted on the financial instability of doctoral candidates and how that impacts their ability to complete their degree, though this work is growing (Sverdlik et al. 2018; Gururaj et al. 2010; Beasy et al. 2019; Ampaw and Jaeger 2012).

The issue of financial precarity in doctoral candidates is complex due to varying program structures not just in different nations, but also due to the different research economies amongst science and humanities disciplines. The financial situations of research students are tied to a range of factors including access to grants, scholarships, and loans; as well as supplemental employment opportunities available within academia (i.e. teaching) and externally. The ranging questions in studies of financial impacts on doctoral progress, differing financial foci, and diverse site contexts, presents challenges in direct comparisons; however, it's clear that increased financial concerns negatively impact completions (Gururaj et al. 2010; Ampaw and Jaeger 2012; Mendoza et al. 2014). 
Despite varying doctoral formats, financial concerns are prevalent amongst research student cohorts globally. In the 2019 Naturesurvey of over 6,000 doctoral students, $75 \%$ of respondents ranked the statement "The difficulty of maintaining a work/life balance" and $67 \%$ ranked "Financial worries after my PhD" in their top five concerns (Lauchlan 2019); results consistent with the 2017 survey (Woolston 2019). No specific question was asked in the Nature study about current financial concerns, but the findings did show that of the $19 \%$ of respondents that indicated having an additional job, more than half $(53 \%)$ said it was to make ends meet (Lauchlan 2019). The Nature report also stated that funding and work-life balance were key barriers to pursuing an academic career (Lauchlan 2019).

In a 2017 Universities Australia survey, 54\% (of 6,206 research students), indicated their financial situation to be "often a source of worry" (Universities Australia 2018) (Fig.1). These similar results to the Nature survey suggest that data collected in Australia, an economically high-ranking OECD nation (McGagh and Wenham 2016), may be representative of the doctoral experience in other OECD countries. In Australia, 65\% of research students receive some form of scholarship, bursary, or stipend (Universities Australia 2018). Generally, the highest value stipends are government-backed, three-year centrally-funded scholarships. Nationally, fewer than $36 \%$ of domestic students receive one of these centrally-funded scholarships (Bentley and Meek 2018) which held a consistent median value of AUD\$26,600 from 2016 to 2019 (Universities Australia 2018; Norton et al. 2018). Most 2019 scholarships provided an income considered at or below the Australian poverty line (Melbourne Institute Applied Economic and Social Research 2019; Davidson et al. 2020). The situation necessitates most students find additional sources of income although, up to $41 \%$ indicate that supplementary work adversely affects their research (Universities Australia 2018).

That PhD students have been living with financial instability is not news to any academic involved in research training. What should be of interest to the broader community, is the extent of current pandemic impacts on this group. By understanding how the pandemic has affected doctoral candidates' financial situation, we can see how this impacts research progress. Our findings provide evidence that more students are reporting severe financial stress, expecting to be forced to disengage, and consequently the pipeline of supply of new graduates into R\&D may be disrupted.

\section{A snapshot of PhDs at the peak of a pandemic.}

During the peak of the pandemic in Australia, several PhD students at a large, research-intensive university became concerned as they witnessed the impact of the disruptor on their cohort. These students decided to collect real-time data to report to their university management to better illuminate the student experience to policy and decision makers. The survey was advertised to all enrolled research students at the University of Sydney, but word of mouth spread quickly and additional doctoral students from many other Australian and international universities also responded. Over 1,000 students responded within the first 24 hours; a quarter of the total cohort of University of Sydney research students (over $1,020)$ responded within 72 hours. That response rate carries a message itself: the students wanted to 
talk about their experience of COVID-19 and the impact it was having on their ability to remain working in research at already low incomes.

The resulting dataset and internal report to the university senior management clearly indicated a more serious impact was occurring than many had realised. The snapshot into the doctoral student experience of the pandemic provided a real-time insight into a shift that was occurring. The data showed that many research students had reached a tipping point and that a potentially large proportion of them were expecting to be forced to abandon their work due to financial hardship. We realised the message needed to be communicated more widely within the research community, particularly to policy-makers in graduate research education and education ministers in governments. Our analysis looks not only at this snapshot in time during a major pandemic but places it in context of pre-COVID studies of the doctoral experience. The shift caused by the pandemic highlights the precarity the students were already existing in and indicates the possibility of far-reaching impacts to our research capacity.

\section{Methods}

The data reported here were collected from $6^{\text {th }}-9^{\text {th }}$ April 2020 via an online survey. The survey received 1076 replies from research students, 1020 responses from verified University of Sydney students, and 56 from students at other universities in Australia and abroad. The 1020 University of Sydney students provided their ID numbers and a detached list of student numbers only were sent by the doctoral students collecting the data to the University for verification. After verification it was determined that the response number represented $24 \%$ of the total research student cohort as at April 2020.

Respondents were self-selecting research students, and broadly demographically representative, incorporating 300 international and 713 domestic students, as well as 843 full-time and 177 part-time students. The original survey and de-identified data are available at http://doi.org/10.25910/5ed06563d9d79

In our analysis, we considered only the 1020 responses from the University of Sydney students as they were the only respondents that had been verified. Some questions were not mandatory, as such not every respondent answered all questions. Where that is the case, the number of responses to the question is reported else the percentage of the entire 1,020 verified Sydney students is given.

In questions where respondents were allowed to indicate multiple selections, for example in the candidature impact question, we counted all instances of a negative selection of a single respondent and converted that to either a 1 (at least one negative response given) or 0 (no negative response given). That means that when calculating the overall disengagement number each respondent is only given a value of 1 in 1,020 regardless of how many negative responses they indicated. The reason was to understand the proportion of the cohort expecting to disengage from studies on a whole. Disengagement is the accepted term to cover a variety of cessation of study and includes, suspension of studies, leave of absence, and 
withdrawal of candidature. Non-completions and student attritions are less often directly from active studies to complete withdrawal and are more usually a process involving leave or suspension first.

In our discussion we have compared the University of Sydney data with pre-COVID data on doctoral students. It is important to remember that the questions asked in the survey were created by doctoral students at the same university and are thus informed by the lived experience of students within the same environment. Whilst the exact questions asked in the Sydney survey and the pre-COVID national and global surveys are not the same, therefore no statistical tests can be run, reasonable comparisons can be made.

The data were collected in the early phase of the COVID-19 pandemic in Australia. Government mandated social distancing restrictions had been rolled out progressively over the previous three weeks, with many organisations severely impacted from $26^{\text {th }}$ March. There was a global, heightened sense of anxiety during the survey period which may have affected some responses.

\section{Results}

\section{Living and financial impacts of COVID-19}

The University of Sydney data shows that $75 \%$ (of 888 respondents) expect to experience financial hardship as a direct result of the pandemic (Fig. 1). Almost a fifth of respondents (154 out of 853 respondents) indicated the pandemic had already resulted in them unable to afford necessities such as utilities, internet connection, and medicines, or they anticipated this impact within 6 months. Additionally, $11 \%$ (of 849 respondents) had already gone without meals or expected to in the next six months as a result of the pandemic. Of those with carer responsibilities, $19 \%$ (of 844 respondents) indicated they could no longer meet the financial cost of supporting others or expected to experience this within 6 months.

Much of the financial impact was driven by changes to supplementary employment, that is income in addition to scholarship stipends. Changes included job losses (18\% of 996 respondents), work and income reduction (19\%), and workload increases without increased pay or even less pay (Fig. 2). Many also said they had undertaken unpaid teaching work to bring courses online for coursework students, further digging into their own research time. Some respondents said they had become entirely reliant on their scholarly stipends or they were living on their partner's income.

In Australia, most universities cap extensions for centrally funded scholarships at 6 months after the initial 3 years, but $66 \%$ of respondents indicated they would need an extension of funding beyond that due to COVID-19 impacts on their research. Scholarship holders were concerned their stipend would cease long before they had completed their degree due to pandemic related delays to their research.

Many (29\% of 858 respondents) had already been unable to meet accommodation costs or expected to face this within 6 months. An additional 30\% (of 1008 respondents) had already, or expected soon, to be 
forced to find alternative accommodation. Notably, $5 \%$ (of 983 respondents) were already, or expected to be soon, experiencing homelessness as a result of the crisis, with $24 \%$ unsure if they may face this. If this $5 \%$ is indicative of the whole Australian research student cohort, potentially over 3,300 doctoral candidates in Australia alone may face homelessness in the coming months.

\section{Impact to candidature}

Many respondents indicated they may be forced to disengage with their studies due to the impacts of the pandemic. Disengagement ranges from blocks of extended leave, through suspension of studies, to complete withdrawal from candidature (Fig. 3). Actual or potential disengagement from candidature as a result of the pandemic was indicated by $45 \%$ of all 1,020 Sydney respondents. The extent of expected disengagement was similar among science-based and arts-based students. It is important to remember that most students do not move directly from active enrolment to withdrawal; when students take suspension of studies or leave of absence, not all return and some end up ultimately withdrawing. Perhaps the most telling figure is that only $18 \%$ (of 899 respondents) agreed with the statement "I do not believe that the COVID crisis will have any impact on my candidature".

\section{Discussion}

\section{The quiet crisis.}

In most research endeavours, generation of new knowledge and technologies are frequently dependent on inexpensive, yet highly-skilled contributions from doctoral candidates. An Australian national thinktank noted that PhD students are frequently a source of "unpaid or lowly-paid research-labour" (Norton et al. 2018). Studies show that research students often feel compelled to undertake unpaid or low-paid work outside of their core research (Cressey 2012), to improve their chances of gaining increasingly rare academic positions (Beasy et al. 2019). The result of systematically facilitating financially precarious behaviour results in a contribution of free or inexpensive labour to the research community. In times of pandemic induced austerity measures, cost-efficient approaches to producing research outcomes such as utilising doctoral candidates for skilled work, may be more frequently employed by organisations struggling to survive deep economic impacts. We have unfortunately become normalised to doctoral candidates often living on minimal incomes, thus it is unsurprising that the additional impacts of the pandemic have resulted in the $\mathrm{PhD}$ crisis falling below the radar on many fronts.

To live in a state of precarity is to be vulnerable to widespread disruptions. When students' concerns around financial stability shift toward expectations of financial hardship, it should be seen as warning. Every year, doctoral students around the world disengage from research candidature for a wide range of reasons. Our findings suggest the level of disengagement, and the short time-frame this disengagement is expected to occur in, are a signal that something deeper and systemic is happening (Fig. 4). 
The 2019 Nature PhD survey (Lauchlan 2019) reported financial related statements in two of the top five concerns of doctoral candidates. The 2017 Universities Australia findings (Universities Australia 2018) indicated just over half of research students find finances to often be a source of worry. The University of Sydney data presented here shows three in four students expect to experience financial hardship as a result of the pandemic. Comparing these findings suggest that the intervention of the COVID-19 crisis has increased the number of students suffering severe financial anxieties.

The consequence of so many doctoral candidates expecting to experience financial hardship is a potentially higher than usual impact on candidature progress. The Australian Department of Education, Skills and Training (DEST 2020) reported that from 2010 to 2014, 20.2\% of research students had dropped out or disengaged during the standard 4-year PhD duration. Our findings suggest a much higher disengagement rate during the next six months (Figure 4). If $45 \%$ of doctoral candidates at one of Australia's leading universities do disengage within the coming months, it is possible that many will not return. We cannot know the real impact for another four years, thus the findings presented here should be taken as a warning not a prediction.

\section{What may be the long-term impacts of the PhD crisis?}

Here we have provided evidence of the doctoral candidate experience of the pandemic. Our findings indicate that the crisis has exacerbated the financial precarity of doctoral candidates, with many now feeling they must abandon research. We may be witnessing the beginning of a wider systemic disruption to the research workforce that drives our knowledge-based economies. It seems prudent to consider the current experience of doctoral students, and the long-term implications of allowing the current impacts to $\mathrm{PhD}$ students to go unchecked. If we do nothing, the potential disruption to research capacity may weaken our societal, public health, and economic recovery. Governments, universities, learned societies, and industry need to produce coherent strategies to address the PhD crisis before it diminishes our research capacity that will be so vital for a good COVID recovery.

\section{References}

Ampaw, F. D., \& Jaeger, A. J. (2012). Completing the three stages of doctoral education: An event history analysis. Research in Higher Education, 53(6), 640-660. DOI https://doi.org/10.1007/s11162-011$9250-3$

Beasy, K., Emery, S., \& Crawford, J. (2019). Drowning in the shallows: an Australian study of the PhD experience of wellbeing. Teaching in Higher Education, 1-17. DOI https://doi.org/10.1080/13562517.2019.1669014

Bentley, P., \& Meek, V. (2018). Development and Future Directions of Higher Degree Research Training in Australia. In J. Shin, B. Kehm, \& G. Jones (Eds.), Doctoral Education for the Knowledge Society 


\section{Conlon, G., Halterbeck, M., \& Julius, J. (2018). The Economic Impact of the Group of Eight Universities, London: London Economics. URL https://www.go8.edu.au/Go8_London-Economics-Report.pdf}

\section{Cressey, D. (2012). PhDs leave the ivory tower. Nature, 484(7392), 20. DOI: $10.1038 / 484020 a$}

Davidson, P., Saunders, P., Bradbury, B., \& Wong, M. (2020). Poverty in Australia 2020: Part 1, Overview. ACOSS/UNSW Poverty and Inequality Partnership Report No. 3. Sydney: ACOSS. URL

http://povertyandinequality.acoss.org.au/wp-content/uploads/2020/02/Poverty-in-Australia-2020_Part1_Overview.pdf

DEST (2020). Higher Degrees by Research Cohort Analysis, 2007-2017. Higher Education Statistics. Canberra: The Department of Education Skills and Employment. URL https://docs.education.gov.au/documents/completions-rates-higher-degree-research-students-cohortanalysis-2007-2017

Evans, T., Bira, L., Gastelum, J. B., Weiss, L. T., \& Vanderford, N. L. (2018). Evidence for a mental health crisis in graduate education. Nature Biotechnology, 36(3), 282-284. DOI

https://doi.org/10.1038/nbt.4089

\section{Gururaj, S., Heilig, J. V., \& Somers, P. (2010). Graduate Student Persistence: Evidence from Three Decades. Journal of Student Financial Aid, 40(1), 31-46.}

Guthrie, S., Lichten, C. A., Van Belle, J., Ball, S., Knack, A., \& Hofman, J. (2018). Understanding mental health in the research environment: A rapid evidence assessment. Rand health quarterly, $7(3)$. URL https://www.rand.org/pubs/research_reports/RR2022.html

Horta, H., Cattaneo, M., \& Meoli, M. (2018). PhD funding as a determinant of PhD and career research performance. Studies in Higher Education, 43(3), 542-570. DOI

https://doi.org/10.1080/03075079.2016.1185406

Juniper, B., Walsh, E., Richardson, A., \& Morley, B. (2012). A new approach to evaluating the well-being of $\mathrm{PhD}$ research students. Assessment \& Evaluation in Higher Education, 37(5), 563-576. DOI https://doi.org/10.1080/02602938.2011.555816 
Kernan, W., Bogart, J., \& Wheat, M. E. (2011). Health-related barriers to learning among graduate students. Health Education, 111(5), 425445. DOI: https://doi.org/10.1108/09654281111161248

\section{Lauchlan, E. (2019). Nature PhD Survey 2019. In S. Learning (Ed.). London: Nature. URL https://figshare.com/s/74a5ea79d76ad66a8af8}

Levecque, K., Anseel, F., De Beuckelaer, A., Van Der Heyden, J., \& Gisle, L. (2017). Work organization and mental health problems in PhD students. Research Policy, 46(4), 868-879. DOI https://doi.org/10.1016/j.respol.2017.02.008

McCarthy, P., \& Wienk, M. (2019). Advancing Australia's Knowledge Economy: Who are the top PhD employers? In AMSI, CSIRO, DATA61, \& Ribit. Melbourne: The Australian Mathmatical Sciences Institute. URL https://amsi.org.au/wp-content/uploads/2019/04/advancing_australias_knowledge_economy.pdf

McGagh, J., Marsh, H, Western, M, Thomas, P, Hastings, A, Mihailova, M, \& Wenham, M. (2016). Review of Australia's Research Training System.: Report for the Australian Council of Learned Academies.

Canberra:ACOLA. URL https://acola.org/wp-content/uploads/2018/08/saf13-review-research-trainingsystem-report.pdf

Melbourne Institute Applied Economic and Social Research (2019). Poverty Lines: Australia, March Quarter 2019. Melbourne: The University of Melbourne. URL https://melbourneinstitute.unimelb.edu.au/publications/poverty-lines

Mendoza, P., Villarreal, P., \& Gunderson, A. (2014). Within-year retention among Ph.D. students: The effect of debt, assistantships, and fellowships. Research in Higher Education, 55(7), 650-685. DOI https://doi.org/10.1007/s11162-014-9327-x

\section{Norton, A., Cherastidtham, I., \& Mackey, W. (2018). Mapping Australian higher education 2018. Melbourne. URL https://grattan.edu.au/report/mapping-australian-higher-education- 2018/}

\section{OECD (2019). Education at a Glance 2019: OECD Indicators. Paris. URL https://www.oecd.org/education/education-at-a-glance/}

Sverdlik, A., Hall, N. C., McAlpine, L., \& Hubbard, K. (2018). The PhD experience: A review of the factors influencing doctoral students' completion, achievement, and well-being. International Journal of Doctoral Studies, 13(1), 361-388. DOI https://doi.org/10.28945/4113 
Universities Australia (2018). 2017 Universities Australia Finances Survey. Melbourne: UA. URL https://www.universitiesaustralia.edu.au/wp-content/uploads/2019/06/180713-2017-UA-StudentFinance-Survey-Report.pdf

\section{Universities Australia (2019). Higher Education: Facts and Figures. Canberra: UA. URL https://www.universitiesaustralia.edu.au/wp- content/uploads/2019/08/190716-Facts-and-Figures-2019-Final- v2.pdf}

Virtanen, V., Taina, J., \& Pyhältö, K. (2017). What disengages doctoral students in the biological and environmental sciences from their doctoral studies? Studies in Continuing education, 39(1), 71-86. DOI https://doi.org/10.1080/0158037X.2016.1250737

Woolston, C. (2019). PhD poll reveals fear and joy, contentment and anguish. Nature, 575(7782), 403406. URL https://media.nature.com/original/magazine-assets/d41586-019-03459-7/d41586-01903459-7.pdf

\section{Declarations}

\section{Ethics approval}

A waiver of consent to use the existing dataset created by doctoral students for internal reporting purposes was granted by The University of Sydney, Research Integrity and Ethics Administration under project number 2020/397 granted on $23^{\text {rd }}$ June 2020.

\section{Author affiliations and ORCID IDs}

\section{All authors are members of The University of Sydney, Australia.}

Rebecca L. Johnson, ORCID 0000-0001-7321-0744

Rebecca.johnson@sydney.edu.au

Ross A. Coleman, ORCID 0000-0003-4136-5914

Ross.coleman@sydney.edu.au 
Nicole H. Batten, ORCID 0000-0002-7255-6169

Nicole.lee@sydney.edu.au

Djuna Hallsworth, ORCID 0000-0003-4621-9828

Djuna.hallsworth@sydney.edu.au

Emma E. Spencer, ORCID 0000-0001-9415-0824

Emma.spencer@sydney.edu.au

\section{Contributions}

Johnson, R. L. was the lead author and provided analysis and project direction. Coleman, R. A. provided expert advice and editing. Batten, N. H., Hallsworth, D., and Spencer, E. E. provided analysis, comments, editing, and figure creation.

\section{Corresponding author}

Correspondence may be addressed to Rebecca Johnson via email at Rebecca.johnson@sydney.edu.au

Funding

Not applicable.

\section{Competing interests}

The authors declare no competing interests.

\section{Ethics}


The pre-existing dataset was accessed by the authors in non-identifiable form. Therefore, the data were not considered personal information and are not subject to New South Wales state privacy legislation or the Australian Federal Privacy Act 1988. Nevertheless, a waiver of consent to use the dataset was sought from the University of Sydney's Research Integrity and Ethics Committee and granted under project number $2020 / 397$ on $23^{\text {rd }}$ June 2020 . To ensure original survey participants could opt-out of any subsequently published findings, the authors ran a short survey in June which was advertised through various University wide channels. No participants from the original survey selected to opt-out.

\section{Availability of data and material}

\section{The dataset analysed for this paper is available on the University of Sydney Data Repository at http://doi.org/10.25910/5ed06563d9d79}

Open comments have not been included in the public dataset to ensure privacy. Correspondence and requests for de-identified open comment data should be addressed to Rebecca Johnson via email at Rebecca.johnson@sydney.edu.au

\section{Code availability}

\section{Not applicable.}

\section{Figures}




\section{Changing Financial Concerns}
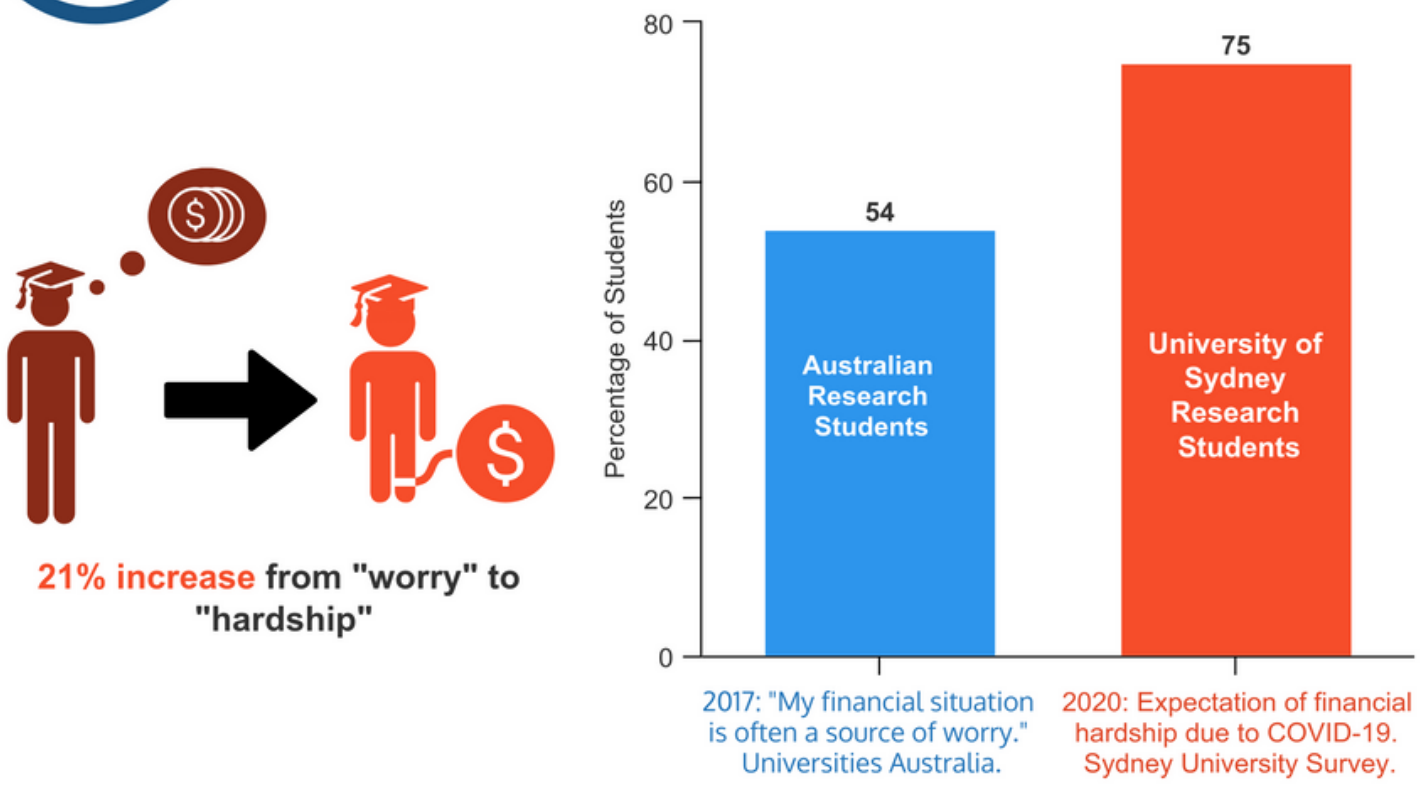

Fig.1 | Comparison of Australian research students attitudes to their finances prior to and during the COVID-19 pandemic.

The 2017 study was conducted nationally by Universities Australia'. The 2020 data were collected by doctoral students at the University of Sydney in April 2020. It is important to note the questions were not the same; the 2017 question asked about finances being a "source of worry", whereas the 2020 survey asked about expectations of financial hardship. A 21\% increase on the total Australian research student cohort at 2018 enrolments represents over an additional $~ 14,000$ research students. The comparison suggests that in Australia, the intervention of the pandemic may push a large number of doctoral candidates into experiencing financial hardships.

\section{Figure 1}

Comparison of Australian research students' attitudes to their finances prior to and during the COVID-19 pandemic. 


\section{Negative Employment Impacts due to COVID-19}

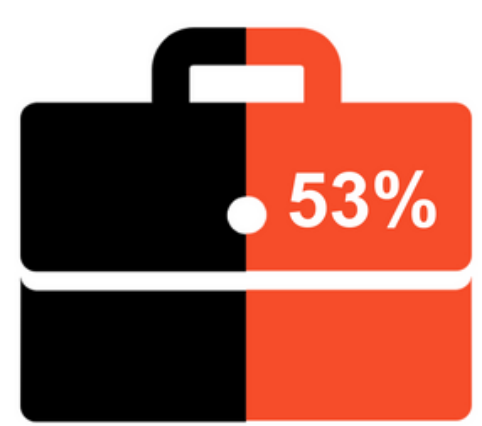

Of 1020 respondents to the University of Sydney survey indicated the COVID. 19 crisis has had some negative impact on their employment.

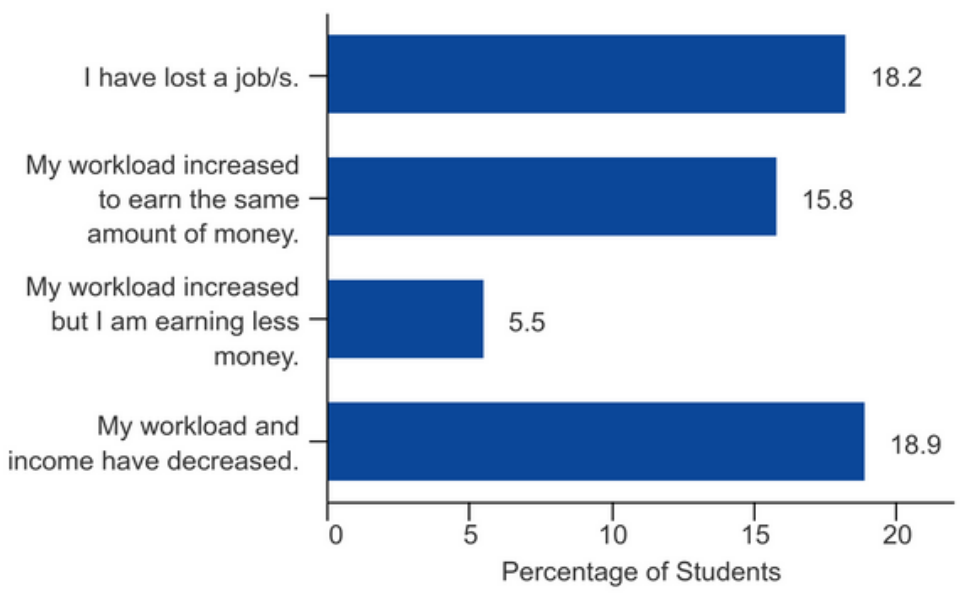

Fig. 2 | Negative impacts on employment arrangements of research students at the University of Sydney as a result of the COVID-19 pandemic.

Employment is defined as income other than scholarships, bursaries, or stipends. Only impacts indicated by over $5 \%$ of respondents are shown in the bar graph. Respondents could select multiple choices. Where workload increased to earn the same amount of money this was generally shown by other results to be due to research students working as teachers and undertaking unpaid work to move coursework units online in response to travel bans and social distancing restrictions.

\section{Figure 2}

Negative impacts on employment arrangements of research students at the University of Sydney as a result of the COVID-19 pandemic. 


\section{Disengagement due to COVID-19}

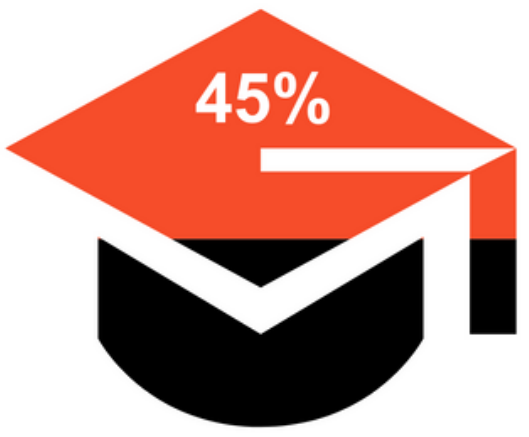

Have already, or expect to within six months, be forced to disengage their research studies as a result of the COVID-19 crisis.

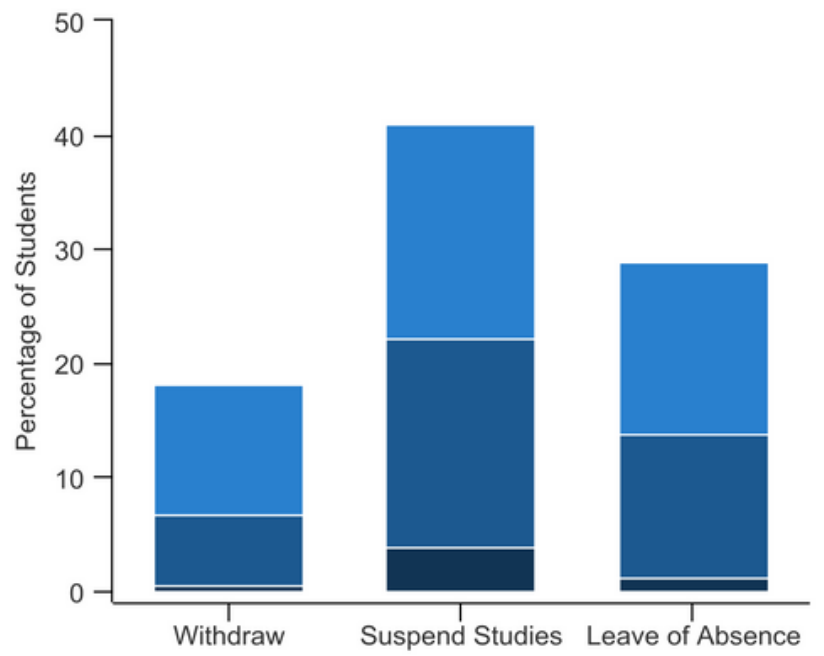

Already have done this due to COVID-19.
Thinking of doing this soon due to COVID-19.

Expect to be forced to within 6-months.

Fig.3 | Disengagement with candidature as a result of the COVID-19 pandemic.

Of the 1020 respondents from the University of Sydney, $45 \%$ indicated they expect to be forced to disengage from research work due to the pandemic. Respondents were able to indicate in each category of: withdraw, suspend, and take leave of absence. A suspension of studies at the University of Sydney is for a minimum of one research period (2-4 months), during which any stipends cease and disengaged domestic students may be eligible for government welfare. Emergency COVID-19 welfare payments in Australia in April 2020 were higher than the income of most scholarships calculated on a weekly basis.

\section{Figure 3}

Disengagement with candidature as a result of the COVID-19 pandemic. 


\section{Disengagement of Candidature}
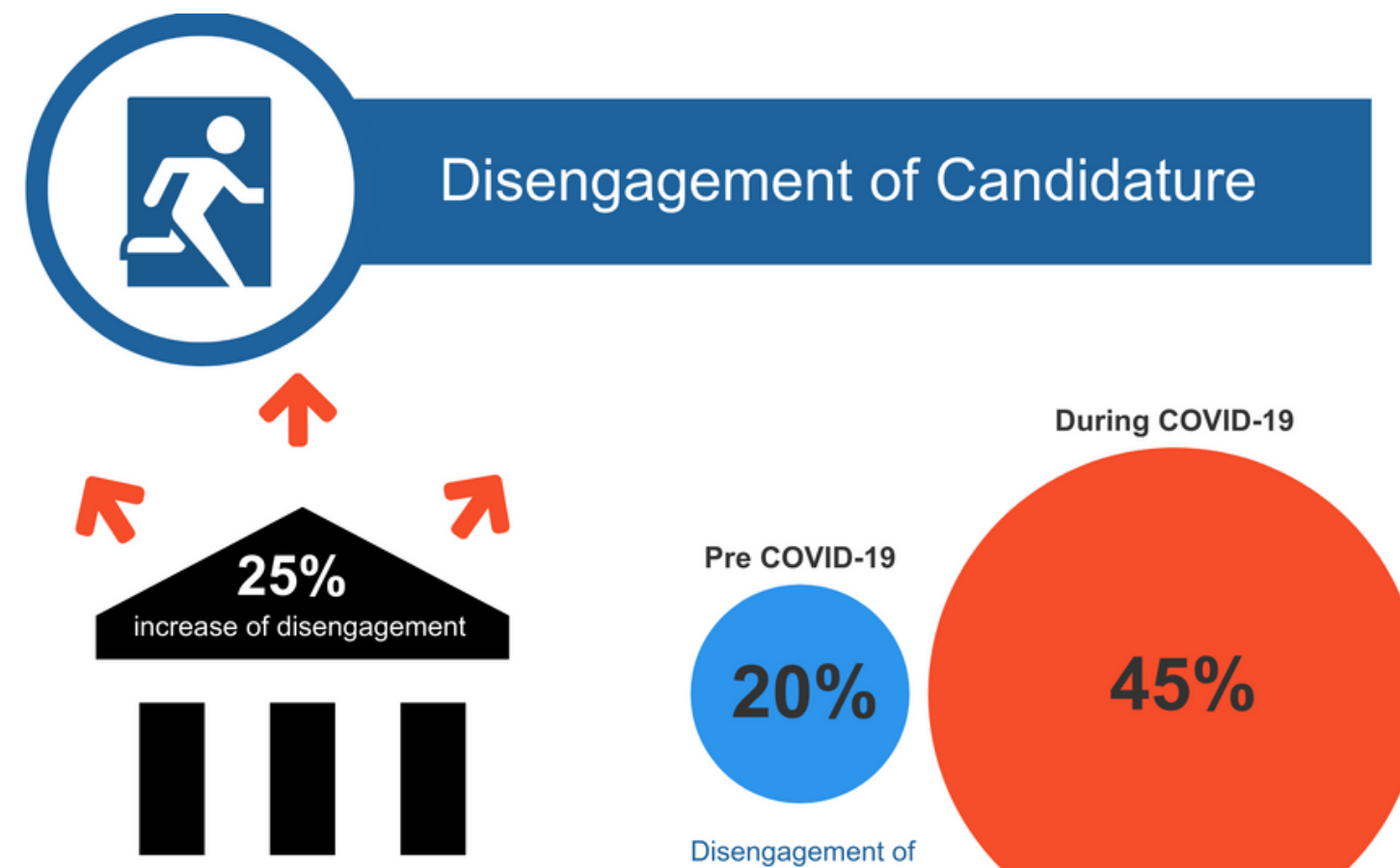

From a 4 year period to a 6 month window.

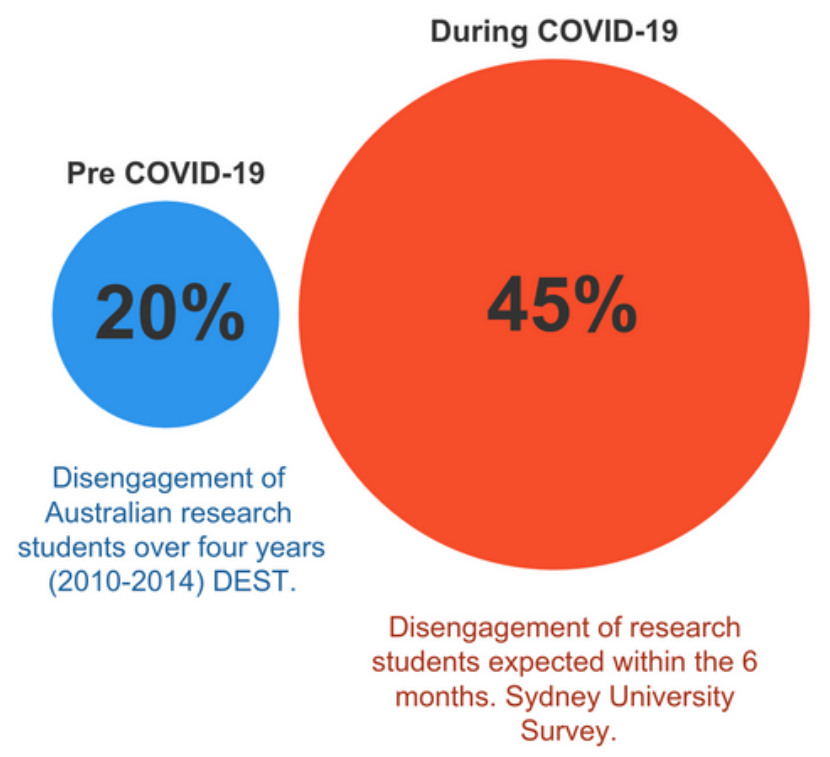

Fig.4 A comparison of disengagement of candidature from research degrees from Australian national figures and the University of Sydney.

Pre COVID-19 disengagement numbers of research students are from the Australian Department of Education, Skills and Training (DEST). Disengagement includes students who have re-enrolled, but dropped out, or never came back after the first year. In both the 2017 DEST and 2020 Sydney University results there was no significant difference between science and arts based disciplines. The doctoral degree in Australia is typically four-years in length for a full time student, thus a disruption may not be accurately observed for four years after the event. Additionally, the DEST results are confirmed enrolment numbers, whereas the Sydney results are the expected outcomes of impact from the COVID19 crisis. Nevertheless, this potential canary in the coal mine warns that over 16,000 doctoral candidates in Australia may be forced to exit the research community.

\section{Figure 4}

Comparison of disengagement of candidature from research degrees from Australian national figures and the University of Sydney.

\section{Supplementary Files}


This is a list of supplementary files associated with this preprint. Click to download.

- TheSydneyCOVID19impactdatasurveyinstrument.pdf

- TheSydneyCOVID19impactdataanonymisedopencommentsremoved.xIsx 